\begin{tabular}{|c|c|c|}
\hline \multirow{3}{*}{$\begin{array}{r}\text { Case Reports in } \\
\text { Gastroenterology }\end{array}$} & \multirow{2}{*}{\multicolumn{2}{|c|}{ Case Rep Gastroenterol 2013;7:245-250 }} \\
\hline & & \\
\hline & $\begin{array}{l}\text { DOI: 10.1159/000351833 } \\
\text { Published online: IVay 28, } 2013\end{array}$ & $\begin{array}{l}\text { ( ) } 2013 \text { S. Karger AG, Basel } \\
1662-0631 / 13 / 0072-0245 \$ 38.00 / 0 \\
\text { www.karger.com/crg }\end{array}$ \\
\hline
\end{tabular}

\title{
Liver Abscesses after Peritoneal Venous Shunt
}

\author{
Hideto Kawaratani Tatsuhiro Tsujimoto Takuya Kubo Yousuke Aihara \\ Toshiaki Takaya Masakazu Uejima Kei Moriya Ryuichi Noguchi \\ Hitoshi Yoshiji Hiroshi Fukui \\ Third Department of Internal Medicine, Nara Medical University, Kashihara, Japan
}

\section{Key Words}

Peritoneal venous shunt - Denver shunt - Liver abscess · Liver cirrhosis · Selective intestinal decontamination

\begin{abstract}
A 70-year-old man was referred to our hospital for high-grade fever with chills. He has visited our hospital for alcoholic liver cirrhosis and diabetes mellitus for over 20 years. Nine months earlier, he had received a peritoneal venous shunt (Denver shunt ${ }^{\circledR}$ ) because of refractory ascites. Laboratory examinations revealed elevated C-reactive protein and liver dysfunction. Ultrasonography and abdominal enhanced computed tomography showed multiple small abscesses in the right lobe of the liver. Blood culture test did not detect the pathogenic bacteria of liver abscesses. The patient was treated with antibiotics for more than 2 months and cured from the infection, but 3 months later, he developed high-grade fever again. $\mathrm{He}$ had a recurrence of multiple small liver abscesses involving both lobes of the liver. He was treated with antibiotics, and the abscesses disappeared within a month. After the antibiotic treatment, he had selective intestinal decontamination with kanamycin. He has had no recurrence of liver abscess for over a year. To our knowledge, this is the first report of liver abscess in a cirrhotic patient with Denver shunt. Clinicians should bear liver abscess in mind when treating patients with high-grade fever and liver dysfunction following Denver shunt implantation.
\end{abstract}

\section{Introduction}

Patients with decompensated cirrhosis usually develop ascites or esophagocardial varices. Ascites are sometimes difficult to control because of low $\mathrm{Na}$ level or dehydration from administering urinary diuresis. Patients with refractory ascites usually receive large-

Hideto Kawaratani, MD, PhD

Third Department of Internal Medicine

Nara Medical University

840 Shijo-cho, Kashihara, Nara 634-8522 (Japan)

E-Mail kawara@naramed-u.ac.jp 
volume paracentesis, and sometimes have a transjugular intrahepatic portosystemic shunt or a peritoneal venous shunt (Denver shunt ${ }^{\circledR}$ ) [1]. Denver shunt is useful for the treatment of refractory ascites with easy craft. Complications mainly include shunt occlusion, post shunt coagulopathy and deep vein thrombosis [2].

Liver abscesses are relatively rare and divided into two main categories: pyogenic and amebic. Pyogenic liver abscesses typically occur from the entrance of pyogenic bacteria into the liver via the portal vein, the biliary tract from an intra-abdominal infection, or hematogenous spread from a systemic infection [3]. The most common features are fever, chills, right upper quadrant pain, and anorexia with no specific symptoms. Risk factors for pyogenic liver abscess are diabetes mellitus, hepatobiliary or pancreatic disease, liver transplantation and trauma [4]. The major sources of pyogenic liver abscess have been reported to include Klebsiella pneumoniae, Escherichia coli and Enterococcus species [5]. Despite the development of treatment, the mortality rate of pyogenic liver abscesses is still high.

We report herein the first case of a patient who, following Denver shunt implantation, developed high-grade fever and multiple small liver abscesses and was consequently treated with antibiotics.

\section{Case Report}

A 70-year-old Mongolian man was referred to our hospital suffering from high-grade fever and chills. He had a past medical history of esophageal varices rupture 20 years before. Since then, he had visited our hospital for alcoholic liver cirrhosis and diabetes mellitus. He received a treatment for ascites caused by liver cirrhosis. Urinary diuresis was not effective because of low Na level and dehydration. As liver function was relatively suppressed (Child class B), he underwent Denver shunt implantation 9 months before presentation. After the operation of Denver shunt implantation, ascites rapidly disappeared. Diabetes mellitus was controlled well (HbA1c 6.3\%) by a oral hypoglycemic agent (glimepiride $3 \mathrm{mg} /$ day).

This time, he developed high-grade fever with chills and without gastrointestinal symptoms. His body temperature was $38.5^{\circ} \mathrm{C}$, but he was hemodynamically stable. Initial laboratory results were as follows: white blood cell count 7,700/ $\mu \mathrm{l}$, hemoglobin $12.9 \mathrm{~g} / \mathrm{dl}$, platelets $5.6 \times 10^{4} / \mu \mathrm{l}$, PT-INR 1.43, CRP $5.0 \mathrm{mg} / \mathrm{dl}$, aspartate aminotransferase (AST) $349 \mathrm{IU} / \mathrm{l}$, alanine aminotransferase (ALT) $353 \mathrm{IU} / \mathrm{l}$, alkaline phosphatase (ALP) $522 \mathrm{IU} / \mathrm{l}$, gamma-glutamyl transferase (GGT) $104 \mathrm{IU} / \mathrm{l}$, total bilirubin (T-bil) $4.3 \mathrm{mg} / \mathrm{dl}$ and albumin $4.1 \mathrm{~g} / \mathrm{dl}$. The stage of liver cirrhosis was classified as Child class B. Abdominal ultrasonography (US) showed multiple small low-echoic lesions in the right lobe of the liver (fig. 1a). These findings were further confirmed by abdominal enhanced computed tomography (CT) that showed peripheral enhancement with central hypodense multiple small lesions in the right lobe of the liver with no ascites (fig. 1b). After admission to our hospital, he underwent echocardiography, chest CT, esophagogastroduodenoscopy and colonoscopy, however, no other sources of infection could be detected. Blood culture was negative and anti-amebic antibody was also negative. He was treated for pyogenic liver abscesses with sulbactam/ cefoperazone for 2 weeks and subsequently changed to levofloxacin for 2 months. The liver abscesses disappeared after the antibiotic treatment and liver function normalized to original levels (AST $44 \mathrm{IU} / \mathrm{l}$, ALT $37 \mathrm{IU} / \mathrm{l}$, ALP $336 \mathrm{IU} / \mathrm{l}$, GGT $85 \mathrm{IU} / \mathrm{l}$ and T-bil $0.9 \mathrm{mg} / \mathrm{dl}$ ). However, 3 months later, he suffered from high-grade fever with chills and no other symptoms. Laboratory results were as follows: white blood cell count $7,400 / \mu \mathrm{l}$, platelets $4.6 \times$

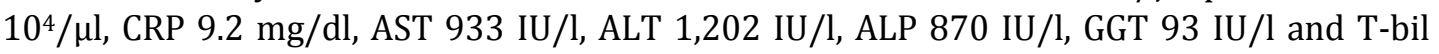
$4.0 \mathrm{mg} / \mathrm{dl}$. Abdominal enhanced CT showed multiple small lesions in both lobes of the liver 
(fig. 2). Blood culture was negative. Sulbactam/cefoperazone had no effects. Meropenem was administered for 2 weeks, followed by levofloxacin for 2 months, and liver function rapidly normalized to original levels (AST 43 IU/l, ALT 30 IU/l, ALP 435 IU/l, GGT 87 IU/l and T-bil $1.8 \mathrm{mg} / \mathrm{dl}$ ). After the levofloxacin treatment, the disappearance of liver abscess was confirmed (fig. 3). We started selective intestinal decontamination by administering kanamycin ( $2 \mathrm{~g} /$ day) to prevent the occurrence of abdominal infection. Since then, he has had no recurrence of liver abscess for over a year.

\section{Discussion}

Denver shunt is useful for patients with refractory ascites. It permits improvement of the patient's quality of life as well as a reduced number of paracenteses. Early complication mainly consists of disseminated intravascular coagulation, and late complications include shunt occlusion, post shunt coagulopathy, deep vein thrombosis, catheter breakage, infection and leakage [2]. Shunt occlusion is the most common complication, affecting approximately $10-15 \%$ of patients [6]. The main cause of occlusion is the accumulation of fibrin and cellular debris that often get impacted after manual compression [7]. Post shunt coagulopathy may occur in up to $5 \%$ of patients following Denver shunt implantation. Infection is estimated to have a lower incidence due to use of prophylactic antibiotics and wound irrigation with aminoglycosides.

Liver abscesses are relatively rare and mainly occur in the patients with diabetes mellitus, hepatobiliary or pancreatic disease, liver transplantation and trauma [4]. The abscesses are multiloculated (about 35\% of the abscesses), and the right lobe is the most common site affected. Only about $30 \%$ of the blood or abscess cultures are positive. US and/or CT of the abdomen are the gold standard diagnostic modalities of liver abscess. Nowadays the main treatment of liver abscess is a combination of targeted antibiotic therapy and US-guided percutaneous drainage [8]. The most commonly used empiric antibiotic is penicillin or thirdgeneration cephalosporin. Abscess culture with sensitivity testing and blood culture provide valuable information for proper treatment. After detecting the pathogenic bacteria from the abscess and/or blood culture, we should change to appropriate antibiotics. The recommended duration of parenteral antibiotic therapy is $2-3$ weeks. Complementary oral antibiotic therapy must then be continued for a further 2-4 weeks or until clinical and radiological follow-up demonstrates complete resolution of the abscess cavity. Some reports suggest that any abscess larger than $5 \mathrm{~cm}$ should be routinely drained [9]. Surgery still plays an important role when percutaneous drainage fails.

Spontaneous bacterial peritonitis (SBP) is the most common infection with a high morbidity and mortality, occurring in $10-30 \%$ of cirrhotic patients with ascites, and is associated with a very high rate of recurrence [10]. The diagnosis of SBP includes checking the cell count and growing bacterial culture obtained from ascites. SBP is related to bacterial translocation [11]. Selective intestinal decontamination with oral antibiotics has been recognized to reduce the occurrence of SBP [12]. Following Denver shunt implantation, ascites may disappear, but bacterial translocation still remains in the patient with liver cirrhosis and infection may occur. In our case, however, he has no ascites because of Denver shunt, SBPassociated pyogenic bacteria in ascites may have transferred to the liver via Denver shunt, and caused sepsis and influenced liver abscess hematogenously. To certify this mechanism, we had to check the ascites inside the Denver shunt, but it was difficult to check ascites from the connection chamber. The reason for abscess formation only in the liver but not in other organs is not clear. In our case, selective intestinal decontamination was able to prevent the 
recurrence of liver abscess. This suggests that liver abscess may be related to bacterial translocation.

In conclusion, our review of the medical literature in PubMed between 1975 and 2012 revealed no report of liver abscess associated with peritoneal venous shunt or Denver shunt. To our best knowledge, this is the first report of liver abscess occurring following Denver shunt implantation. Diagnosis of liver abscess is not difficult by US and/or enhanced CT. When treating patients with Denver shunt who suffer from high-grade fever and liver dysfunction, clinicians should keep liver abscess in mind. We should actively perform a blood examination and US and/or enhanced CT examination.

\section{Disclosure Statement}

The authors have no conflicts of interest to declare.

\section{References}

1 Runyon BA; Practice Guidelines Committee, American Association for the Study of Liver Diseases (AASLD): Management of adult patients with ascites due to cirrhosis. Hepatology 2004;39:841-856.

2 Martin LG: Percutaneous placement and management of the Denver shunt for portal hypertensive ascites. AJR Am J Roentgenol 2012;199:W449-W453.

-3 Rahimian J, Wilson T, Oram V, Holzman RS: Pyogenic liver abscess: recent trends in etiology and mortality. Clin Infect Dis 2004;39:1654-1659.

4 Kaplan GG, Gregson DB, Laupland KB: Population-based study of the epidemiology of and the risk factors for pyogenic liver abscess. Clin Gastroenterol Hepatol 2004;2:1032-1038.

5 Wong WM, Wong BC, Hui CK, et al: Pyogenic liver abscess: retrospective analysis of 80 cases over a 10-year period. J Gastroenterol Hepatol 2002;17:1001-1007.

6 Perera E, Bhatt S, Dogra VS: Complications of Denver shunt. J Clin Imaging Sci 2011;1:6.

7 Bratby MJ, Hussain FF, Lopez AJ: Radiological insertion and management of peritoneovenous shunt. Cardiovasc Intervent Radiol 2007;30:415-418.

8 Kurland JE, Brann OS: Pyogenic and amebic liver abscesses. Curr Gastroenterol Rep 2004;6:273-279.

$\checkmark 9$ Bamberger DM: Outcome of medical treatment of bacterial abscesses without therapeutic drainage: review of cases reported in the literature. Clin Infect Dis 1996;23:592-603.

-10 Llovet JM, Bartolí R, Planas R, Cabré E, Jimenez M, Urban A, Ojanguren I, Arnal J, Gassull MA: Bacterial translocation in cirrhotic rats. Its role in the development of spontaneous bacterial peritonitis. Gut 1994;35: 1648-1652.

11 Garcia-Tsao G, Lee FY, Barden GE, Cartun R, West AB: Bacterial translocation to mesenteric lymph nodes is increased in cirrhotic rats with ascites. Gastroenterology 1995;108:1835-1841.

12 Pleguezuelo M, Benitez JM, Jurado J, Montero JL, De la Mata M: Diagnosis and management of bacterial infections in decompensated cirrhosis. World J Hepatol 2013;5:16-25. 


\begin{tabular}{|c|c|c|}
\hline \multirow{3}{*}{$\begin{array}{r}\text { Case Reports in } \\
\text { Gastroenterology }\end{array}$} & \multirow{2}{*}{\multicolumn{2}{|c|}{ Case Rep Gastroenterol 2013;7:245-250 }} \\
\hline & & \\
\hline & DOI: 10.1159/000351833 & $\begin{array}{l}\text { (c) } 2013 \text { S. Karger AG, Basel } \\
\text { www.karger.com/crg }\end{array}$ \\
\hline
\end{tabular}
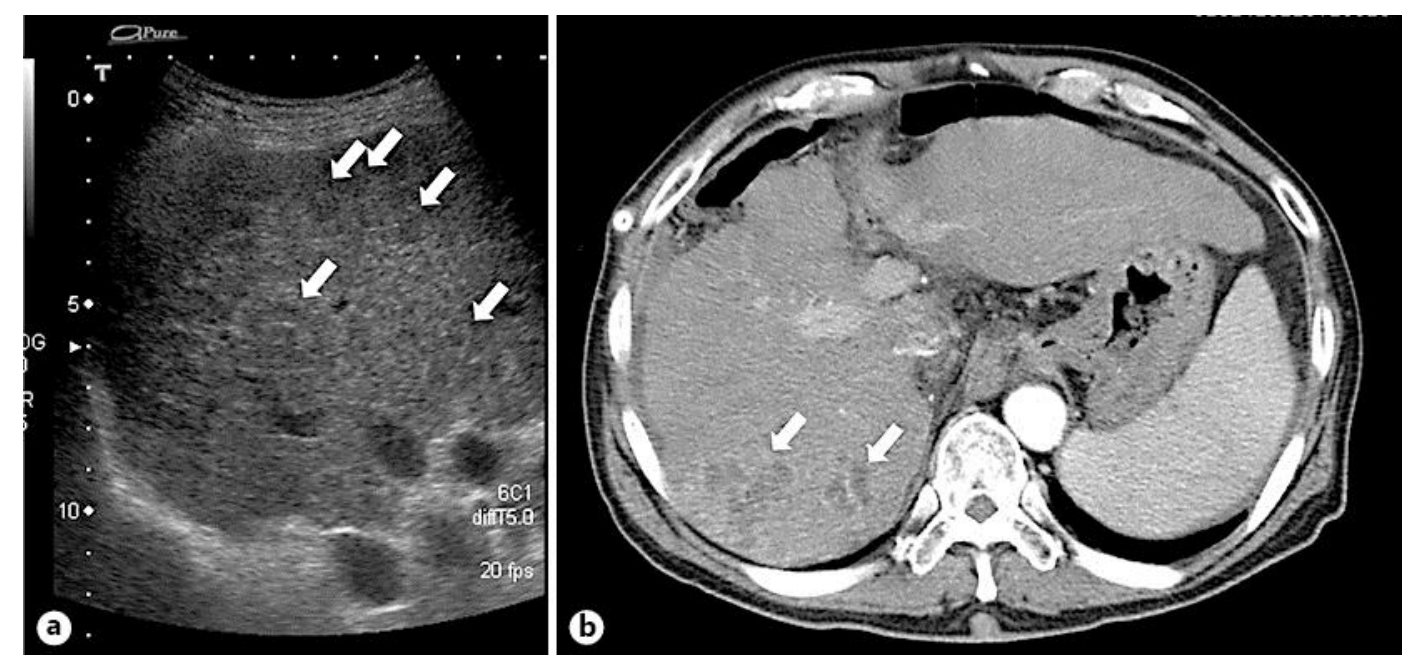

Fig. 1. a Abdominal US showed multiple small low-echoic lesions (arrows) in the right lobe of the liver. b CT showed peripheral enhancement with central hypodense multiple small lesions (arrows) in the right lobe of the liver.

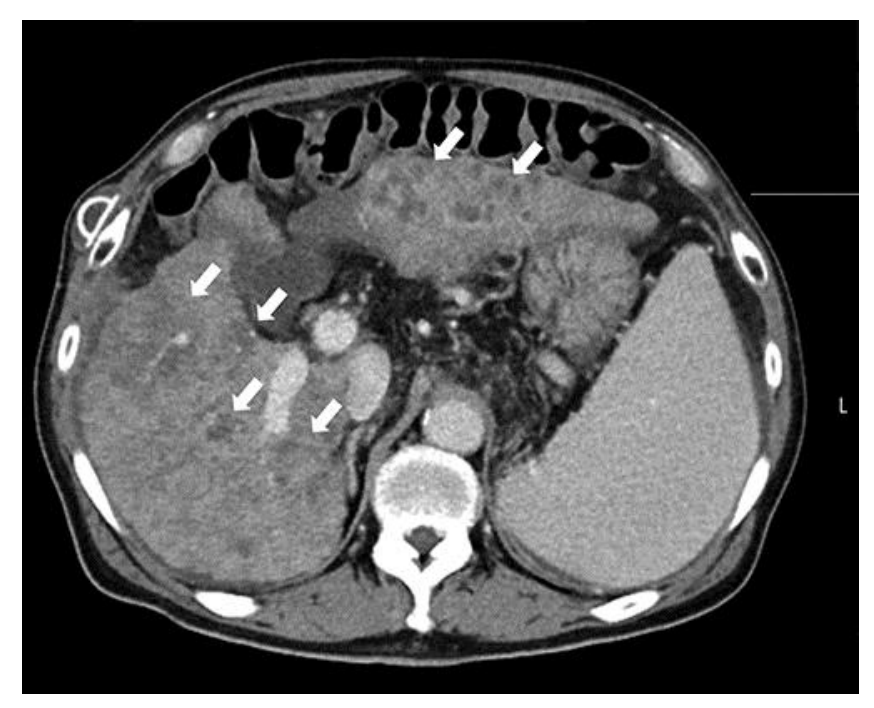

Fig. 2. CT showed multiple small lesions (arrows) in both lobes of the liver. 


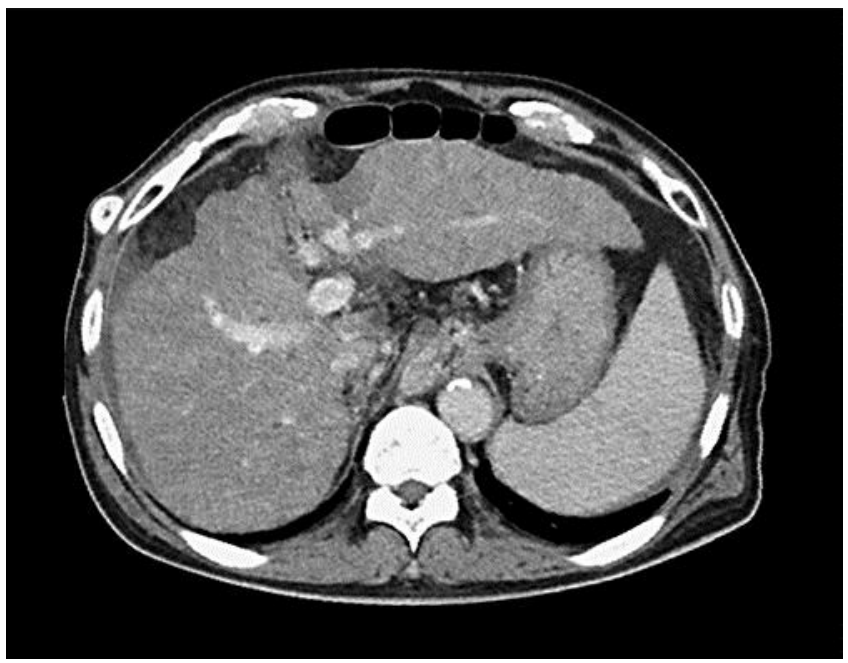

Fig. 3. The liver abscess had disappeared after antibiotic treatment. 